\title{
9 Archiving the Databody: Human and Nonhuman Agency in the Documents of Kurenniemi
}

\author{
Geoff Cox, Nicolas Malevé, and Michael Murtaugh
}

\section{6/24/1996, 9:44 p.m., Personal}

Will she (either of them) share the love of pornography? Or at least, art? I shall present myself to both of them as a geniality self-flagellat\%n [sic] machine. Just one bottle tonight, ok? I shall invite them on my journey of change, showing the way ahead. Immortality. I will let them sniff and sneak through my archives.

The archive has increasingly become to be understood as a cultural paradigm, transfiguring notions of collective memory and the complexities of historical and temporal processes. This essay seeks to align some of these ideas with computational processes through Constant's (Preliminary Work) Toward an Online Archive, a set of (ongoing) experimental explorations of the archive of Erkki Kurenniemi that probes the vast amount of diverse materials with a variety of machinic processes. ${ }^{1}$ The work is extensively documented in a $\operatorname{logbook}^{2}$ and begins with an entry that makes reference to Kurenniemi's own invitation to "sniff and sneak through my archives," from his (electronic) diary entry of 1996.

\section{Active Archives}

Preliminary Work builds on the ongoing Active Archives project initiated in 2006 by Brussels-based art and media collective Constant (of which Malevé and Murtaugh are members), which engages the politics of open data and introduces core values associated with free software development related to the decentralization of resources and the ownership of infrastructures. ${ }^{3}$ Put simply, to Constant, archives are understood as a collection of material that is not merely readable but also writable and executable, and thus subject to certain ethical standards. ${ }^{4}$ Their working approach is not to follow standardized archiving procedures of ordering and classifying, but to offer a series of speculations on the specific qualities of the materials by running computer programs. Nor is this reducible to something like Google's PageRank algorithm that makes sense of the vast archive of the Internet in distorted ways to "reify" knowledge and make sure 
that expression is linked to the market. ${ }^{5}$ Rather, the programs produce emergent forms of knowledge-they operate as "probes," in their terms-more a project of forensics than historiography. ${ }^{6}$

As work began on the project, it became immediately evident that Kurenniemi had documented his life but not archived it in a traditional sense. Despite the lack of a consequent or single ordering however, multiple orderings of the material still existed. As work continued, a number of core problematics became evident related to giving "direct access" to the digital materials of the archive: (1) legality — how to address potential restrictions on its visibility owing to questions of privacy, copyright, and a frequently intimate sexual nature; (2) quantity — how to take on the vast amount and diversity of the material; and (3) fidelity-how whatever form of access given would then relate to Kurenniemi's ideal of an "artificial consciousness." In each case, the problems were embraced as central themes, and part of a unique opportunity to situate the work before the archive had fully formed, somewhat in the spirit of Kurenniemi's intention to archive for future use. ${ }^{7}$

Arguably, the challenge for constructing the contemporary archive is to construct one that is decentralized and remains active in the way that meanings are able to be continually produced rather than fixed in the geopolitics of time and space. Thus the archive is not some dusty repository of fixed meanings there to be uncovered and ordered into some kind of narrativized version of official history, but more so a contested and dynamic force field of potential human and machine "interpretation." In the case of Preliminary Work, interpretation of the archive is explored through performative "programming" techniques to uncover (and compile) aspects of what is not directly apparent in the material—beyond visual and tactile apperception. By running both human and machine processes, Constant speculate on what and how knowledge is produced in an expanded field.

This is more a process of performing knowledge, perhaps (somewhat in the spirit of Foucault's Archaeology of Knowledge $e^{8}$ in seeking hitherto undiscovered knowledge, or seeking to discern what constitutes emergent knowledge) - a process of knowing and unknowing materials. This is an important issue inasmuch as it establishes the interaction of material conditions and the materiality of bodies. The archive produces, or rather performs, new kinds of human and nonhuman materialities in the powerknowledge matrix. This further resonates with "media archaeological" methods (outside the scope of this essay but very present elsewhere in the book) and the work of Friedrich Kittler in particular, who argues for combining material conditions and epistemology, as, for example, in acknowledging the software used to write a particular essay, ${ }^{9}$ or in this case, we would argue, the wiki with which we collaboratively write this text. ${ }^{10}$ In this way the tools that are used for archiving can be registered as part of the archive; as, for instance, in the case of Preliminary Work, through the extensive use of 


\section{PROPERTY OF THE MIT PRESS \\ FOR PROOFREADING, INDEXING, AND PROMOTIONAL PURPOSES ONLY}

software repositories/archives such as Gitorious, with all scripts carefully documented for future modification and reuse. ${ }^{11}$

The iterative approach taken therefore suggests an epistemological understanding of archives beyond objects and relations-the conventional tropes of archives-to something far more behavioral, contingent, and recursive, and more like the machinic logic that underpins Kurenniemi's thinking in the first place. For example, below are some extracts from Kurenniemi's diary that treat his physical relationship to his lover's body as if it were an abstract machine to which logical operations could be performed (using addition or multiplication) or recomposed in subsystems to be further processed:

7/15/1996, 9:48 p.m., Personal

$\mathrm{X}^{12}$ slept here last night. The obvious problem arose as she admitted that she'd like to multiply whereas I only want to add.

7/15/1996, 10:19 p.m., Personal

Now I must disassemble $\mathrm{X}$ in acceptable subsystems and then process them one by one.

The reflexive way of working described thus far is also well suited to the specific character of Kurenniemi's obsessive documentation of his own life to produce a meta-archive of all human life (described at length elsewhere in this book). His self-archive is not only intended to form a template for human life in the future, but to enable human life itself to be made executable, using algorithms yet to be invented. Perhaps these probes are some early expressions of discovering what is not yet known, with complexity building on simple initial understandings of memory allocation. For instance, $d u$ - $h$ (disk usage, with "human" option) is a very basic and common tool for interrogation of the data stored on a hard drive. It simply dumps a list of the names of files and folders, with the amount of disk space used. The process recurses into each subfolder with the disk space usage overlapping and complexifying. ${ }^{13}$ A further example of understanding the allocation of memory is the JavaScript emulation of the "find" command (see http://kurenniemi.activearchives.org/logbook/?p=284). By playing the script in the browser, the user reruns the command but this time within his or her own system and computer's memory. Rather than simply visualizing the output of a command, it is performed, with series of controls allowing the user to examine the process: by playing, pausing, or modifying the speed. As the archive is heavy, by running the command and seeing how the browser has to struggle to process it, one can feel the weight of the archive.

In this essay, we take the archive-body to be an exemplar of an active archive, not as fixed materials or a mere collection of objects but something more like source code that is modifiable and shareable-something that forks future paths of execution and recursion in the spirit of the Kurenniemi's overall fantasy of reconstructing life (by the 


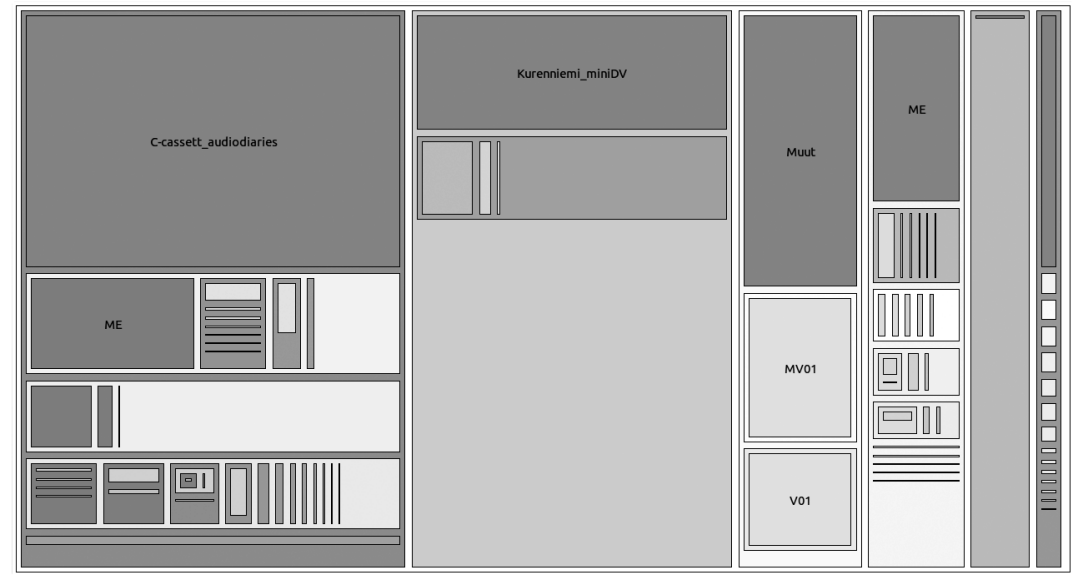

Figure 9.1

The output of the du command visualized as a treemap.

year 2048). More to the point, the quantum computer-yet to be built—is imagined by Kurenniemi to be able to make sense of the documents he has been recording and capturing in his daily life and stored into hard memory for later access and reallocation, merging biological and computational processes.

\section{Data Bodies}

Human memory and computer memory are endlessly compared in ways that confuse the idea of the archive as both a place for remembering and forgetting, as repository for both the storage and deletion of historical data. Not least the dubious use of analogies of computational systems to human memory reveal the collective fantasy of the ability to model the human organism at all levels of operation. This is not simply the story of the behaviorist tendencies of computer science but one that also occurs in numerous discourses that attempt to understand the human mind-as if it were merely a computer. It is at once a piece of science fiction and part of the concrete history of computational logic and the first ideas of what constitutes a human computer.

In his short essay on memory in Software Studies, Warren Sack refers to Turing's first description of how a machine might remember what it is doing and decide what to do next:

It is always possible for the computer to break off from his [sic] work, to go away and forget all about it, and later to come back and go on with it. If he does this he must leave a note of instructions ... explaining how the work is to be continued. ... The note of instructions must enable him to carry out one step and write the next note. Thus the state of progress of the computation at any stage is completely determined by the note of instructions and the symbols on the tape. ${ }^{14}$ 


\section{PROPERTY OF THE MIT PRESS \\ FOR PROOFREADING, INDEXING, AND PROMOTIONAL PURPOSES ONLY}

Sack continues that these simple procedures correlate with bureaucracy, as if the logic underpinning the thinking prescribes mindless tasks such as involved in the use of files, folders, directories, stacks, lists, and even the automated management of memory (so-called garbage collection ${ }^{15}$ ) - that are encapsulated in desktop metaphors and office software. ${ }^{16}$ The archive simply adds to the list in terms of the garbage that constitutes it, as well as its disciplinary character and regulatory practices that constitute the body as both subject and object of the system that produces the shit in the first place. It is almost as if the body can be understood as simply an input-output machine and that human subjects merely execute their programmed instructions and scripts. ${ }^{17}$

Of course, the body is thoroughly implicated in archives in more complex ways, as Foucault makes explicit, ${ }^{18}$ but our point is also to acknowledge how the body is part of computational processes, not reducible to them. Kurenniemi has his own particular views on this:

The transformation of physical sex into spiritual sex. So to say from hardware sex to software sex. Why do you need genitals when there is a shorter route ... to manipulate your brain? ... It's better to let these organic computers work the way they were developed to work. Nothing prevents your immortal soul to move over the new hardware. Don't spoil your old one. ${ }^{19}$

To Kurenniemi, the body is an obsolete envelope that humanity will leave behind in the necessary course of evolution, but having done so it will fall into eternal boredom. The archive of the body will be the only distraction available, the only way to hold on to the memory of what it was once like to have a body. However, it is more a question not of leaving the body behind but of understanding its active presence in complex and material assemblages that extend its, and our, understanding of agency-in coconstituted form. Kurenniemi recorded his life intensively and in particular his bodily activity (such as walking, sitting, eating, defecating, urinating, having sex, singing, yelling, sleeping), yet the various recording devices clearly cannot be abstracted away from the material realities they are archiving and while being archived simultaneously. This position is somewhat similar to the one that Wolfgang Ernst takes (in this volume too), in which the technological devices themselves are the archive, and kept functionally operative to maintain "nonhistoricist memory." ${ }^{20}$ The archive is not to be taken as an "institution of frozen memory" but is made operative by its understanding as an apparatus. But how do the probes affect the nature of what they uncover, especially in the most intimate settings? We wish to consider the recording as part of a wider assemblage of active agents.

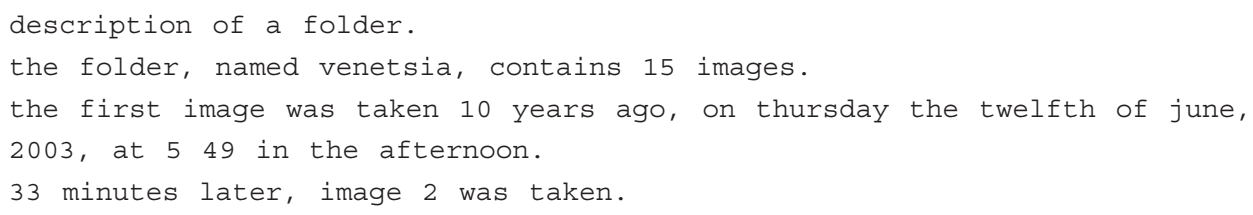


PROPERTY OF THE MIT PRESS

FOR PROOFREADING, INDEXING, AND PROMOTIONAL PURPOSES ONLY

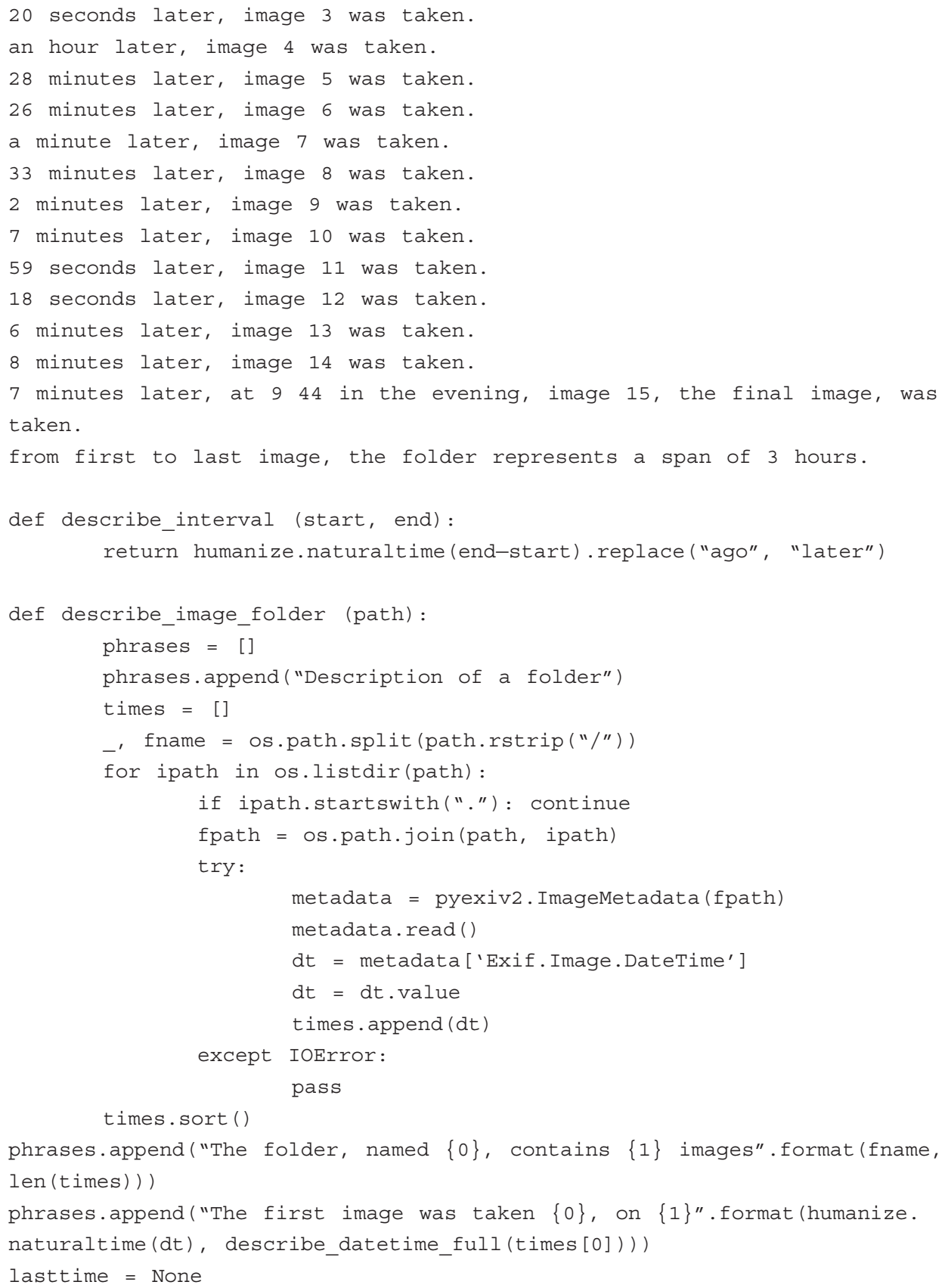




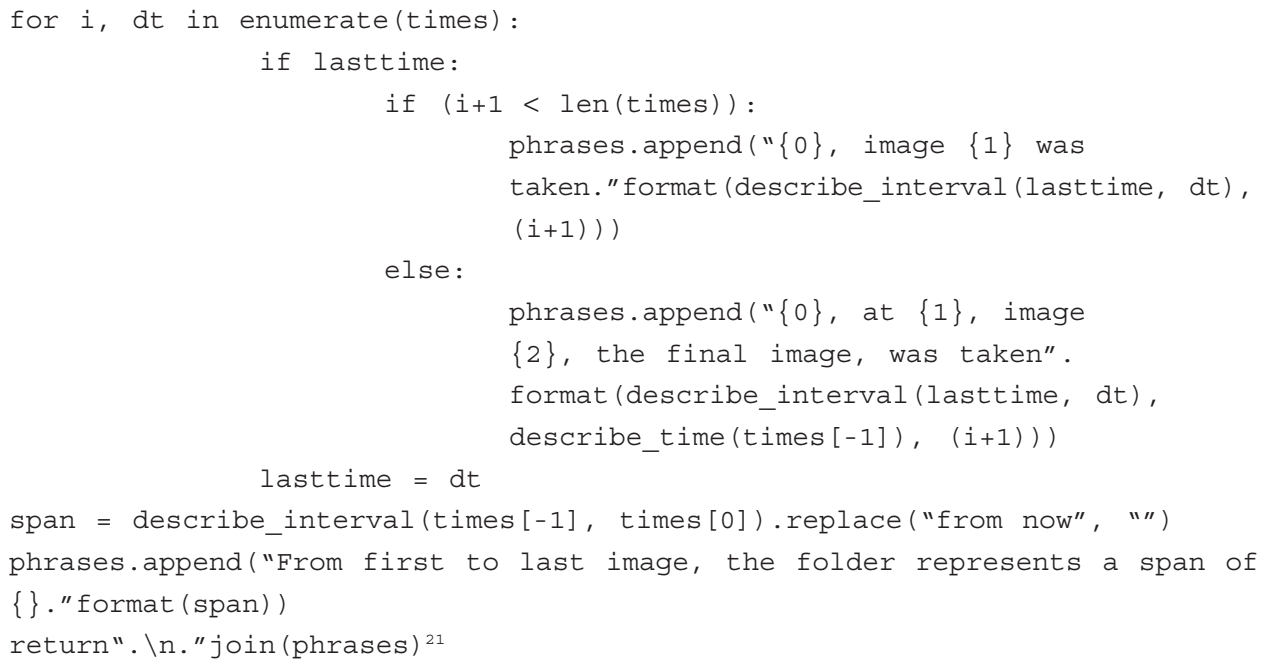

\section{Material Agency}

The recent attention to dynamic matter and "new materialities" establishes this "interaction" of the apparatus and forms of agency that are "more than human." Describing what she refers to as "agential realism," Karen Barad explains:

Knowing is not about seeing from above or outside or even seeing from a prosthetically enhanced human body. Knowing is a matter of inter-acting. Knowing entails specific practices through which the world is differentially articulated and accounted for. In some instances, "nonhumans" (even being without brains) emerge as partaking in the world's active engagement in practices of knowing. ... Knowing entails differential responsiveness and accountability as part of a network of performances. Knowing is not a bounded or closed practice but an ongoing performance of the world. ${ }^{22}$

Historical and biological agents are bound together in new assemblages that allow for new conceptualizations of power-knowledge. But this goes further than the assertion that power largely determines the body through various forces such as the archive, as Foucault suggests. Rather, the boundaries of human and nonhuman agency-distributive agency-are challenged by the acceptance of power as demonstrating a broader view of materiality and the dynamic qualities of matter. ${ }^{23}$ Material agency includes bodies and social structures but also technologies as in the case of computational nano-/biotechnologies presenting new human machine assemblages and hybrid forms. Barad's claim is that agency is emergent through the "inter-action" of elements and signals different and distinct agencies acting together. In the case of the archive we need to account for social practices and human bodies, but also various nonhuman agents as 
part of the wider apparatus. Our example is the way a program can be understood only as part of a distributive agency that includes the programmer, computer, network, factory worker, and wider scientific, military, economic, medical, political system within which data is materialized.

Kurenniemi's archive contains an impressive body of documents (audio, video, written diaries, audio diaries) that describe his various thought processes, not least related to one of his main obsessions, sexuality. Visibility seems to be a precondition of this. If sex was unrecorded, Kurenniemi seemed barely interested in the experience, and yet the paradox is that only a few of these documents can now be seen. To be made public, the rights that are attached to the documents have to be cleared, and many of the people pictured in these documents object to their public dissemination. In Preliminary Work, these legal documents, the agreements between the different stakeholders, do not represent obstacles to overcome to obtain the most complete visibility of the documents gathered and produced by Kurenniemi, but rather an epistemological challenge to which other kinds of visibility can be explored. In this respect, we are forced to reach beyond the limits of the human eye and the predominance of the visuality in knowledge production.

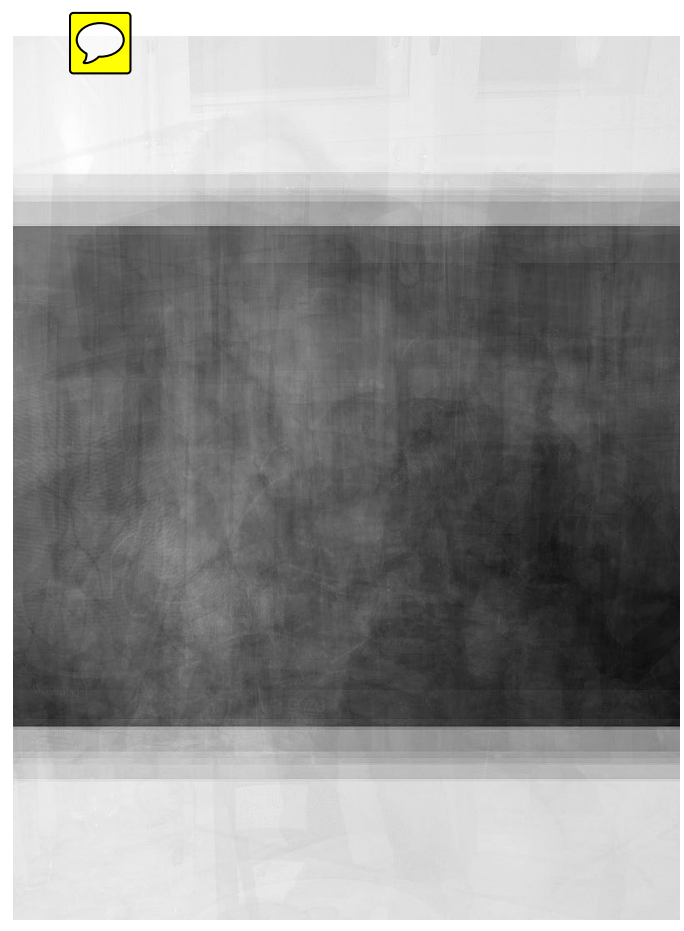

Figure 9.2

Average image: http://kurenniemi.activearchives.org/logbook/?p=215. 


\section{PROPERTY OF THE MIT PRESS \\ FOR PROOFREADING, INDEXING, AND PROMOTIONAL PURPOSES ONLY}

The strength of the usual legal approach is that it forces us to consider images as sites of attachment for various people. Therefore when legal protocols forbid the publication of the images until the people who are pictured have been contacted and agree to their public dissemination, the effect is not only one of closure but also one of disclosure. It forces us to reconsider the image not as a given object that has been captured and framed, but as a relation and inter-active assemblage of distributed agents that all have "rights." Attributing "rights" to any one agent when agency is shared between diverse objects would seem to be an oversimplification that the legal system blindly attempts to enforce, ultimately without recourse to the complex materialities in operation. If the images cannot be displayed, then other information can be disclosed to us by agents who are not subject to normative legal or human visual protocols. This also opens up a broader ethics of open content and the ideologies related to cultures of sharing and reworking materials (e.g., free software and open licenses such as GNU GPL). ${ }^{24}$ Furthermore, the various legal instruments that constrain practices through the regulation of intellectual property extend to life itself (in the case of patents over DNA) with overt biopolitical dimensions. Hence what is demonstrated is a lack of sophistication of the legal system to account for more complex materialities as they remain locked into conservative normativity and a limited worldview related to ownership and property rights.

Leaving aside the "retinal" approach to the image, other agents open up alternative possibilities, for instance in the use of probes and experiments to expose computerized traces of Kurenniemi's life, allowing us to feel temporal intensities, other carnal distances and proximities, other lines of desire. Agency in this sense is attributed to more than the actions of human bodies but also the tools, technical devices, algorithms, the performativity of the network itself, the archive as apparatus, and so on. ${ }^{25}$ In such ways, the probes begin to uncover aspects of what is not directly apparent in the material, revealing aspects of what is not yet known.

\section{Active Forensics}

When we use the term active, it is not by contrast to an archive that would otherwise remain passive, but to indicate inter-active assemblages. No archive remains passive as such. If one looks carefully at the work of an archivist, one can see that he or she is always working on the archive for it to "remain the same," attempting to halt the inevitable decaying processes of all objects, and even taking acts of preservation to be a form of vandalism. ${ }^{26}$

Documents are kept in conditions that need constant care and attention, and even for it to remain a fixed point of reference, it changes constantly. Furthermore, just as no two things in the physical world are precisely the same, data forensics reveals that documents are also different at the scale of discreet bits of information. ${ }^{27}$ They exist 
as complex "media" forms that are subject to "forensic materiality" and processes of mediality. As Giorgio Agamben has elsewhere explained with respect to gesture, mediality is "the process of making a means visible as such." ${ }^{28}$ It is also worth noting that the etymology of media reveals its roots in anatomy with its "medical" understanding as cure from diseases, as well as the more contemporary meaning of translation from one media to another, and thus takes on a forensic register. By creating connections between documents and excluding other connections, by contextualizing and decontextualizing them, the archive rewrites its contents, changes the way the documents are seen or read and interpreted. There is a content-authoring inherent in any archival work. If we use the term active archive to describe our activities, it is meant more to emphasize processes that are inherent to the archive and to push its actions to the extreme. If an archive is in a permanent state of mediality, always in temporality, always rewriting itself, an active archive is an attempt to describe strategies and tools that amplify and diversify this process, to reveal medialities-indeed we would stress the archive as a software machine: as readable, writable, and executable. And therefore the material is provided with the ability to "speak" for-itself. In a sense, code always speaks, inasmuch as it is a particular form of language that says and does what it says at the same time. ${ }^{29}$

More precisely, we understand active archival practices as something close to the way that Eyal Weizman and Thomas Keenan define forensics in Mengele's Skull, as more than simply the scientific method of gathering and examining information about the past but as opening up an ethical dimension.

Forensics is, of course, not simply about science but also about the presentation of scientific findings, about science as an art of persuasion. Derived from the Latin forensis, the word's root refers to the "forum," and thus to the practices and skill of making an argument before a professional, political or legal gathering.

In classical rhetoric, one such skill involved having objects address the forum. Because they do not speak for themselves, there is a need for a translation, mediation, or interpretation between the "language of things" and that of people. This involves the trope of prosopopeia-the figure in which a speaker artificially endows inanimate objects with a voice. ${ }^{30}$

The rise of forensics thereby gives an insight into how inanimate objects have been ventriloquized, their testimonies voiced by human witnesses on behalf of the objects. Kurenniemi, who, since suffering a stroke has lost the ability to speak, might be similarly "animated" through the various agents that constitute his archive well before 2048.

\section{Algorithmic Archiving}

Even if our goal is not to make an argument about Kurenniemi's material as such, the idea of the archive as a forum where the material has a chance to speak seems 


\section{PROPERTY OF THE MIT PRESS \\ FOR PROOFREADING, INDEXING, AND PROMOTIONAL PURPOSES ONLY}

productive. Much of Preliminary Work has been devoted to developing the conditions for various conversations to unfold between Kurenniemi's materials, tools, and scripts, between different authorial agents, and in this way to extend agency toward a "flat ontology" as a technique to examine the various materialisms at work. By using the phrase "flat ontology," we adopt the terminology of object-oriented ontology to suggest that all things exist equally and that humans are not necessarily at the center of knowledge production. But this is not our position as such, as clearly the various agents, including the archive, are structured in ways in which power-knowledge is unevenly distributed, and the figure of Kurenniemi, too, seems to persist as a centralizing force. Rather, our point is that the act of archiving can be performed by other nonhuman objects that coconstitute the archive as a whole, and that recognition of this exposes subtle dynamics of power. As part of the developmental process, the following blog post describes some early ideas about computational tools as interlocutors in this way, not least as a pragmatic solution to the problem of scale and the limits of human perception.

We can't access the elements of the archive individually. Too many of them. We need intermediaries. People to tour us through. Tools, filters, sensors. That will listen, see, aggregate and separate, connect and disconnect, assemble and disassemble.

With the intermediaries, we will have to learn and speak the same language, accept the gaps, sense the priorities. The tools. They won't see as we see through our eyes, they won't listen as we listen, they will perceive through different dimensions, they will count time with another anxiety.

As our intermediaries, our tools will be our interlocutors. ${ }^{31}$

The algorithms become conversational agents that perform forensic operations and then explain phenomena in their own informational terms, uncovering the archive for what it is: essentially, a collection of data. For example, data gallery is an attempt to give a first form to this "conversation" beyond the limits of visual representation.

Imagine a picture.

An horizontal picture 2592 pixels wide and 1944 pixels high.

The picture was taken on the 06th of November 2004 at 21h56:37. The document set contains 45732 pictures by Erkki Kurenniemi for the year 2004. Erkki took 223 pictures in 2004 between the hours of 9 and 10pm. Of the 45732 pictures present in the dataset, Erkki took 33712 at night.

In the folder where this file is located, there are 28 other pictures. They have been taken between $21 \mathrm{~h} 56: 32$ and the next day at 19h21:18. The folder Harrin bileet can be seen as a sequence of 21 hours 24 minutes 46 seconds of the life of a man of 63 years 4 months at the date the picture was taken.

It took $1 / 40$ th second for the camera to take the picture. The blink of an eye. ${ }^{32}$

The interface gives access not to the images gathered and produced by Kurenniemi in their usual form but to different agential points of view on the images. Computer 
vision algorithms like face detection, contour detection, color measurement, and metadata extraction are combined to give a multifaceted commentary on the image file.

The data gallery interface is a grid that contains the different outputs of the algorithms. The first cell contains a threshold filtered representation of the dominant RGB component of the image, as digital images, such as those recorded by Kurenniemi's digital cameras, are typically represented as streams of pixels of red, green, and blue (RGB) components. ${ }^{33}$ Next to this, a cell displays a representation of the contours detected in the image. The detection is done using the library OpenCV using the Hough transform. ${ }^{34}$ The next cell contains an image showing rectangles where faces have been detected, or an indication of their absence according to the algorithm. ${ }^{35}$ In the second row, the date of capture of the photograph is displayed on a field of the average color of the image. Next to this, a description appears that is produced from additional information recorded by the digital camera and stored in the image as metadata. ${ }^{36} \mathrm{~A}$ final cell displays, when available, a histogram of the image's relative values of red, green, and blue components.

The point is that none of these outputs have the final word on the image. They complement, question, confirm, and sometimes contradict each other. The image is not what is shown on the page but what exists between knowledge produced by the different outputs. One can see the contours of bodylike forms and the location of faces, can see the zones with the dominant red color. The EXIF information reports on the time of the day, and the average color gives a background mood for the scene. The original image doesn't appear on the viewer's retina but it begins to exist in the imagination, and each image can be understood to contain its own archive.

Algorithms do not simply "read" information in images or sound files, they do not only "detect" features in data; they also generate new forms, new shapes, or new sounds. For instance, when working on the collection of audio cassette recordings made by Kurenniemi in the 1970s, as part of the DATA Radio project (a second installment of the Preliminary Work project focusing on the Kurenniemi's audio cassette diaries), ${ }^{37}$ numerous ways to reorganize the material according to its internal structure were explored. That is how Spectrum sort is conceptualized..$^{38}$

Spectrum sort applies a fast-Fourier transform (FFT) to Kurenniemi's digitized cassette recordings, breaking the sound into one-tenth of a second fragments that are each then characterized by their predominant (loudest) frequency band. Moments where the predominant frequency is low are grouped together, as are moments with a predominantly middle or higher frequency. The fragments are reassembled and played as a continuous movement through the material of a single recording. When the algorithm reports back, it sequentially reorganizes its findings. Applied to a particular cassette, C4004, the reassembled recording begins with moments of mostly quiet fragments of ambience just before or between moments of speech. One hears the ambience of a quiet room or the low rumbling of Kurenniemi's automobile and background traffic. 


\section{PROPERTY OF THE MIT PRESS}

FOR PROOFREADING, INDEXING, AND PROMOTIONAL PURPOSES ONLY

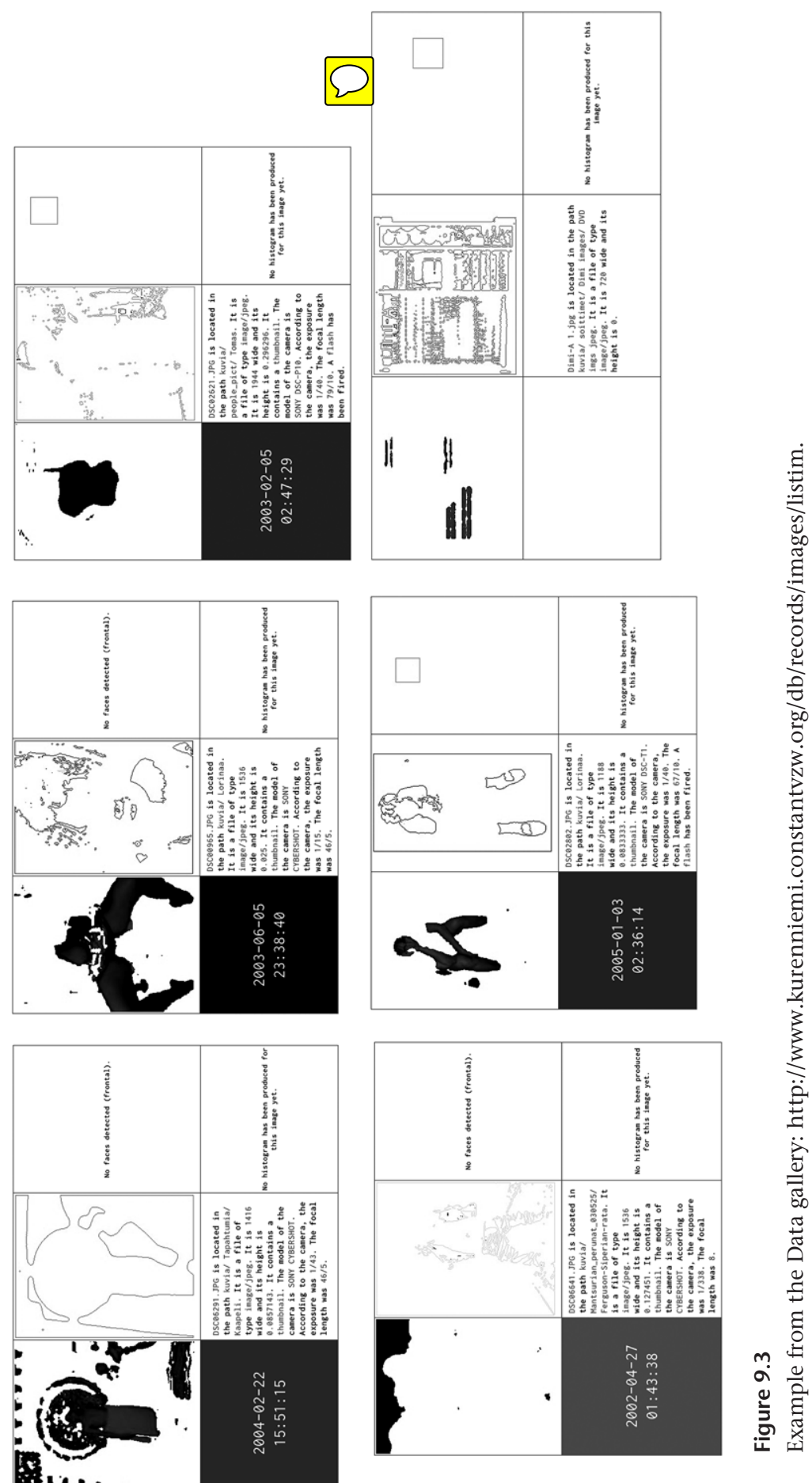


Near the end of the rearrangement, bursts of predominantly tonal fragments combine, producing a striking stream of singing/chanting syllables. Besides a certain uncanny sense of artificial sound synthesis, the algorithmic arrangement reveals a use and quality of Kurenniemi's voice that is characteristic of the recordings. The algorithm's and the human's voices combine.

\section{Postscript}

According to Kurenniemi, algorithms hold the potential to regenerate materials and life itself. Whereas the body is taken to be an ephemeral hardware product at an early evolutionary stage, quantum computers are imagined to be able to store our subjectivities and liberate us, once the databody can be fully executed. Somewhat like Kurenniemi, and building on her notion of "quantum entanglements," Barad also imagines the future possibilities afforded by quantum computation, in which previously unsolvable problems will be able to be solved by computers yet to be discovered. She points to the way that this requires a metaphysical leap of imagination in understanding cells as computational devices able to self-organize and adapt like biological systems. ${ }^{39}$

For Barad, this represents more than simply a description of ever more computational power; it also represents pressing concerns about control, governance, and security. It is perhaps the first steps in quantum cryptography that we currently witness in the revelations about the extent of data surveillance by government agencies such as the NSA (National Security Agency) in the Edward Snowden case and others—sniffing and sneaking around our archives covertly under the pretense of counterintelligence. ${ }^{40}$ More to the point, Preliminary Work reminds us of the dubious ethics of such practices and an expanded sense of the archive as both a technology of subjection and potential freedom from constraints. As Foucault explains, the archive is not simply a tool of repression but one that is active in the constitution of the subject under the regime of "governmentality." ${ }^{41}$ In addressing the archive with algorithms, rather than seeing an algorithm as a "pure" transformation from one representation to another, the algorithm can be understood as something more complex that amplifies and creates other objects with their own properties and qualities, further generating possibilities for the production of knowledge derived from archives in the broadest sense. This also demonstrates the distributive agency of things and new epistemological challenges for data made active as part of the body politic.

\section{Notes}

1. Brussels based art and media collective Constant's engagement with Kurenniemi's archive materials began with a commission as part of Kurenniemi: In 2048 as part of Documenta 13 (2012) 


\section{PROPERTY OF THE MIT PRESS \\ FOR PROOFREADING, INDEXING, AND PROMOTIONAL PURPOSES ONLY}

Archiving the Databody

and continued with DATA radio as part of Systemics \#1 for Kunsthal Aarhus (2013), and as part of Erkki Kurenniemi: Toward 2048 for Kiasma, Museum of Contemporary Art, Helsinki (2013-2014). See http://activearchives.org/wiki/Erkki_Kurenniemi:_In_2048.

2. http://kurenniemi.activearchives.org/logbook/.

3. http://activearchives.org/wiki/Manifesto_for_an_Active_Archive.

4. http://activearchives.org/.

5. Reification is the "thingification" of social relations, or the extent to which social relationships are expressed between objects in the market.

6. Thomas Keenan and Eyal Weizman, Mengele's Skull: The Advent of a Forensic Aesthetics (Berlin: Sternberg Press, 2012).

7. As Morten Søndergaard also mentions in his essay for this volume, "Kurenniemi's archive is not about what happened in the past, but about what might happen in the future."

8. Michel Foucault, Archaeology of Knowledge, trans. A. M. Sheridan Smith (London: Routledge, 2002). First written in 1969 as L'archéologie du savoir.

9. See Friedrich Kittler, "There Is No Software," 1995, http://www.ctheory.net/articles.aspx?id=74.

10. In its wiki form, the essay can be read at http://activearchives.org/mw/index. php?title=Archiving_the_Data-body:_human_and_nonhuman_agency_in_the_documents_of _Kurenniemi\&action=edit.

11. http://gitorious.org/kurenniemi.

12. Editors' note: We have redacted the female first name to ensure anonymity.

13. http://www.kurenniemi.constantvzw.org/logbook/.

14. Warren Sack, "Memory," in Software Studies, ed. Matthew Fuller (Cambridge, MA: MIT Press, 2008), 188.

15. In computer science, "garbage collection" refers to a form of automatic memory management. See http://en.wikipedia.org/wiki/Garbage_collection_\%28computer_science\%29.

16. Sack, "Memory," 190.

17. Geoff Cox and Alex McLean, Speaking Code: Coding as Aesthetic and Political Expression (Cambridge, MA: MIT Press, 2012), 103.

18. As does Allan Sekula's "The Body and the Archive," first published in October 39 (winter 1986): 3-64, http://www.jstor.org/stable/778312.

19. Transcript from the audio diary cassette C4076, April 1973. Furthermore, this reminds us of the artist Orlan's posthuman mantra "my body is my software"; http://www.orlan.eu/.

20. Wolfgang Ernst, "E-Kurenniemics: Becoming Archive in Electronic Devices," in this vol. 


\section{PROPERTY OF THE MIT PRESS \\ FOR PROOFREADING, INDEXING, AND PROMOTIONAL PURPOSES ONLY}

21. See http://activearchives.org/wiki/Description_of_a_folder.

22. Karen Barad, Meeting the Universe Halfway (Durham, NC: Duke University Press, 2007), 149.

23. For instance, as described by Jane Bennett in Vibrant Matter: A Political Ecology of Things (Durham, NC: Duke University Press, 2010).

24. http://www.gnu.org/licenses/gpl.html.

25. In addition to agency, the root of agencer is to arrange, as an assemblage, even curate. For more on this, see Iain Hardie and Donald Mackenzie, "Assembling an Economic Actor," in Sociological Review 55: 1 (2007): 58. Thanks to Magnus Lawrie for this reference.

26. The Museum of Ordure make this explicit in their "preservation policy" statement, to explain the acceleration of "decay" in their online archive:

Everything that is represented in the Museum of Ordure is subject to the vagaries of an uncontrolled internal process which slowly deforms and disables all information held in the museum. This is comparable to the decaying processes which affect all artifacts in museums, regardless of all attempts at preservation: the retouching, repainting, cleaning, etc., which are incorporated risks to the purity of artifacts when first acquired by museums. Even "successful" renovations are subject to periodic changes resulting from shifts in conservation policies. Eventually (and in accordance with the fallibility of memory) artifacts are institutionally, progressively, determinedly and inadvertently altered by acts of conservation (sometimes unintentional acts of institutional vandalism) until they cease to be recognizable as the objects first acquired. Of course in both cases-in the virtual environment and in the material world - the processes of generation, decay, and entropy are paramount. Museums are by this definition charged with achieving the impossible. (http://www.ordure.org/collection/ preservation/)

27. An extensive discussion of "forensic materiality" and its relation to digital storage media can be found in Matthew Kirschenbaum's Mechanisms: New Media and the Forensic Imagination (Cambridge, MA: MIT Press, 2012).

28. Giorgio Agamben, Means without End: Notes on Politics (Minneapolis: University of Minnesota Press, 2000), 58.

29. For more on this connection to speech, see Cox and McLean, Speaking Code.

30. Weizman and Keenan, Mengele's Skull, 28.

31. http://kurenniemi.activearchives.org/logbook/?p=308.

32. http://kurenniemi.activearchives.org/logbook/?page_id=521.

33. Dominant color: When the difference between the color components of a pixel results in a value higher than 30 for the dominant color, the pixel is printed. For example, when an image has red as the dominant component, all the pixels of the image where the red value is 30 above the green and the blue components are printed.

34. Because of imperfections in the image, it is often nontrivial to group the extracted edge features to an appropriate set of lines, circles, or ellipses. The purpose of the Hough transform is to address this problem by making it possible to perform groupings of edge points into object candidates by performing an explicit voting procedure over a set of parameterized image objects (Linda 
G. Shapiro and George Stockman, Computer Vision [Upper Saddle River, NJ: Prentice Hall, 2001], 304).

35. Face recognition is done using a Haar classifier, first proposed by Paul Viola and improved by Rainer Lienhart.

36. Exchangeable image file format (EXIF): https://en.wikipedia.org/wiki/Exchangeable_image _file_format.

37. DATA Radio, an interactive stream of audio and text: http://kurenniemi.activearchives.org/ dataradio/.

38. See Spectrum sort: http://activearchives.org/wiki/Spectrum_sort.

39. Barad, Meeting the Universe Halfway, 384.

40. See http://en.wikipedia.org/wiki/National_Security_Agency and http://en.wikipedia.org/ wiki/Edward_Snowden.

41. See Michel Foucault, The Government of Self and Others: Lectures at the Collège de France 19821983 (Basingstoke: Palgrave, 2010). 
PROPERTY OF THE MIT PRESS

FOR PROOFREADING, INDEXING, AND PROMOTIONAL PURPOSES ONLY 